\title{
A Numerical Investigation of Thermal Diffusion Influence on Soot Formation in Ethylene/Air Diffusion Flames
}

\author{
HONGSHENG GUO ${ }^{\mathrm{a}, *}$, FENGSHAN LIU ${ }^{\mathrm{a}}$, GREGORY J. SMALLWOOD ${ }^{\mathrm{a}}$ and ÖMER L. GÜLDER ${ }^{\mathrm{b}}$ \\ ${ }^{a}$ Combustion Research Group, Institute for Chemical Process and Environmental Technology, National Research Council of Canada, \\ 1200 Montreal Road, Building M-9, Ottawa, Ont., Canada K1A OR6; ${ }^{\mathrm{b}}$ Institute for Aerospace Studies, University of Toronto, \\ 4925 Dufferin Street, Toronto, Ont., Canada M3H 5 T6
}

\begin{abstract}
Thermal diffusion, caused by temperature gradients, tends to draw lighter molecules to warmer regions and to drive heavier molecules to cooler regions of a mixture. The influence of thermal diffusion on soot formation in coflow laminar ethylene/air diffusion flames is numerically investigated in this paper. Detailed reaction mechanisms and complex thermal and transport properties are employed. The fully elliptic governing equations are solved. Radiation heat transfer from the flames is calculated by the discrete-ordinates method coupled to an SNBCK-based wide band model. A simplified two-equation soot model is used. The interactions between soot and gas-phase chemistry are taken into account. The thermal diffusion velocities are calculated according to the thermal diffusion coefficients evaluated based on multicomponent properties.

The results show that thermal diffusion does affect soot formation in ethylene/air diffusion flames. Although the effect on soot formation in pure ethylene/air flame is not significant, the influence is enhanced if lighter species, such as helium, are added to the fuel or the air stream. The peak integrated soot volume fraction doubles if thermal diffusion is not taken into account in the simulation of the flame with helium addition to the air stream.
\end{abstract}

Keywords: Combustion; Thermal diffusion; Laminar flame; Soot; Simulation; Radiation

\section{INTRODUCTION}

Heat and mass transport processes have been shown to be of great importance for soot formation (McLintock, 1968; Schug et al., 1980; Axelbaum et al., 1988; Axelbaum \& Law, 1990; Gülder et al., 1996; Glassman, 1998; Guo et al., 2002a). Thermal diffusion (Soret effect), caused by temperature gradients in a mixture, gives an additional term in the diffusion velocity of a chemical species. It tends to draw lighter molecules to hot regions and to drive heavier molecules to cold regions of the mixture.

In a pioneering work, Dixon-Lewis (1968) observed that the thermal diffusion flux of hydrogen could be of the same order of magnitude as the ordinary diffusion flux, caused by concentration gradients, in a hydrogen/air flame. The same observation was made by Greenberg (1980) in the study of one-dimensional hydrogen/air flames using a one-step chemistry model and phenomenological expressions for the thermal diffusion coefficients. Later it was found by Warnatz (1982) that the laminar flame speeds of both lean and rich hydrogen/air flames were lower when thermal diffusion was taken into account, although only the thermal diffusion fluxes of atomic and molecular hydrogen were considered in the simulation. In the study of vortex-flame interactions in hydrogen jet diffusion flames, Hancock et al. (1996) showed that the thermal diffusion effect couldn't be neglected in the numerical simulation. Recent studies of Ern and Giovangigli $(1998,1999)$ further indicated the importance of thermal diffusion in various reactive flows. In the paper of Ern and Giovangigli (1998), it was shown that thermal diffusion was important not only for the prediction of structures of hydrogen/air and methane/air Bunsen flames, but also for the prediction of NO in a counterflow methane/air flame. Being different from the result of Warnatz (1982), the study of Ern and

*Corresponding author. Tel.: + 1-613-991-0869. Fax: +1-613-957-7869. E-mail: hongsheng.guo@nrc-cnrc.gc.ca 
Giovangigli (1999) indicated that for hydrogen/air flames, while the speeds of lean flames were lower, those of rich flames were higher when thermal diffusion of all species was considered. The influence of thermal diffusion on the speeds of methane/air flames was negligible. More recently, Williams (2001) revealed that thermal diffusion caused an increase in the predicted extinction strain rate of methane/air counterflow flames.

In spite of the importance of thermal diffusion, little attention has been paid to the influence of thermal diffusion on soot formation processes. It was totally neglected in some studies (McEnally et al., 1998; Smooke et al., 1999; Bennett et al., 2001), while only the thermal diffusion of light species (such as $\mathrm{H}_{2}$ and $\mathrm{H}$ ) was taken into account in other studies, such as our two recent papers (Guo et al. (2002a,b) and Kennedy et al. (1996)). To our knowledge, the relative influence of thermal diffusion on soot formation has not been reported previously in the literature.

In the present paper, soot formation processes in a pure ethylene/air and four helium or argon diluted ethylene/air coflow laminar diffusion flames are simulated. The objective is to investigate the relative influence of thermal diffusion on soot formation. We employ the primitive variable method in which the fully elliptic governing equations are solved with detailed gas-phase chemistry and complex thermal and transport properties. The effects of soot inception, growth and oxidation on gas-phase chemistry are taken into account. For the soot kinetics process, a simplified two-equation soot model is used. Radiation heat transfer from $\mathrm{CO}_{2}, \mathrm{CO}, \mathrm{H}_{2} \mathrm{O}$ and soot is calculated using the discrete-ordinates method coupled to an SNBCK-based wide band model.

\section{NUMERICAL MODEL}

The flame configuration studied is a coflow axisymmetric laminar diffusion flame. The fuel stream flows from the centre pipe, and the oxidant stream flows from the annular concentric space. Except for the pure ethylene/air diffusion flame, flames with helium or argon addition to the fuel or air stream are also studied.

\section{Gas-phase Governing Equations}

The numerical model solves the fully elliptic governing equations for the conservation of mass, momentum, energy, gas species mass fractions, soot mass fraction and soot number density. In cylindrical coordinates $(r, z)$, the governing equations for the gas-phase are (Kuo, 1986):

Continuity:

$$
\frac{\partial}{\partial r}(r \rho v)+\frac{\partial}{\partial z}(r \rho u)=0 .
$$

Axial momentum:

$$
\begin{aligned}
\rho v \frac{\partial u}{\partial r} & +\rho u \frac{\partial u}{\partial z} \\
= & -\frac{\partial p}{\partial z}+\frac{1}{r} \frac{\partial}{\partial r}\left(r \mu \frac{\partial u}{\partial r}\right)+2 \frac{\partial}{\partial z}\left(\mu \frac{\partial u}{\partial z}\right) \\
& -\frac{2}{3} \frac{\partial}{\partial z}\left(\frac{\mu}{r} \frac{\partial}{\partial r}(r v)\right)-\frac{2}{3} \frac{\partial}{\partial z}\left(\mu \frac{\partial u}{\partial z}\right) \\
& +\frac{1}{r} \frac{\partial}{\partial r}\left(r \mu \frac{\partial v}{\partial z}\right)+\rho g_{z} .
\end{aligned}
$$

Radial momentum:

$$
\begin{aligned}
\rho v \frac{\partial v}{\partial r}+ & \rho u \frac{\partial v}{\partial z} \\
= & -\frac{\partial p}{\partial r}+\frac{\partial}{\partial z}\left(\mu \frac{\partial v}{\partial z}\right)+\frac{2}{r} \frac{\partial}{\partial r}\left(r \mu \frac{\partial v}{\partial r}\right) \\
& -\frac{2}{3} \frac{1}{r} \frac{\partial}{\partial r}\left(\mu \frac{\partial}{\partial r}(r v)\right)-\frac{2}{3} \frac{1}{r} \frac{\partial}{\partial r}\left(r \mu \frac{\partial u}{\partial z}\right) \\
& +\frac{\partial}{\partial z}\left(\mu \frac{\partial u}{\partial r}\right)-\frac{2 \mu v}{r^{2}}+\frac{2}{3} \frac{\mu}{r^{2}} \frac{\partial}{\partial r}(r v)+\frac{2}{3} \frac{\mu}{r} \frac{\partial u}{\partial z} .
\end{aligned}
$$

Energy:

$$
\begin{aligned}
c_{p}(\rho v & \left.\frac{\partial T}{\partial r}+\rho u \frac{\partial T}{\partial z}\right) \\
= & \frac{1}{r} \frac{\partial}{\partial r}\left(r \lambda \frac{\partial T}{\partial r}\right)+\frac{\partial}{\partial z}\left(\lambda \frac{\partial T}{\partial z}\right) \\
& -\sum_{k=1}^{K K+1}\left[\rho c_{p k} Y_{k}\left(V_{k r} \frac{\partial T}{\partial r}+V_{k z} \frac{\partial T}{\partial z}\right)\right] \\
& -\sum_{k=1}^{K K+1} h_{k} W_{k} \omega_{k}+q_{r} .
\end{aligned}
$$

Gas species:

$$
\begin{aligned}
\rho v \frac{\partial Y_{k}}{\partial r}+\rho u \frac{\partial Y_{k}}{\partial z}= & -\frac{1}{r} \frac{\partial}{\partial r}\left(r \rho Y_{k} V_{k r}\right)-\frac{\partial}{\partial z}\left(\rho Y_{k} V_{k z}\right) \\
& +W_{k} \omega_{k}, \quad k=1,2, \ldots, K K,
\end{aligned}
$$

where $u$ and $v$ are the velocities in axial (z) and radial $(r)$ directions, respectively; $T$ the temperature of the mixture; $\rho$ the density of the mixture (soot and gas); $W_{k}$ the molecular weight of the $k$ th gas species; $\lambda$ the mixture thermal conductivity; $c_{p}$ the specific heat of the mixture under constant pressure; $c_{p k}$ the specific heat of the $k$ th gas 
species under constant pressure; $\omega_{k}$ the mole production rate of the $k$ th gas species per unit volume; $p$ the pressure. It should be pointed out that the production rates of gas species include the contribution due to the soot inception, surface growth and oxidation (see the next section). Quantity $h_{k}$ denotes the specific enthalpy of the $k$ th gas species; $g_{z}$ the gravitational acceleration in the $z$ direction; $\mu$ the viscosity of the mixture; $Y_{k}$ the mass fraction of the $k$ th gas species; $V_{k r}$ and $V_{k z}$ the diffusion velocities of the $k$ th gas species in $r$ and $z$ directions; and $K K$ the total gas-phase species number. The quantities with subscript $K K+1$ correspond to those of soot. As an approximation, the thermal properties, obtained from JANAF thermochemical tables (Chase et al., 1985), of graphite are used to represent those of soot.

The last term $q_{r}$ on the right-hand side of Eq. (4) is the source term due to radiation heat transfer. It is obtained by the discrete-ordinates method coupled to a statistical narrowband correlated-K (SNBCK)-based wide band model for the properties of $\mathrm{CO}, \mathrm{CO}_{2}, \mathrm{H}_{2} \mathrm{O}$ and soot (Liu et al., 1999). The spectral absorption coefficient of soot is obtained by Rayleigh's theory for small particles and the refractive index of soot due to Dalzell \& Sarofim (1969) is $5.5 f_{v} / \lambda$, with $f_{v}$ being the soot volume fraction and $\lambda$ the wavelength.

The diffusion velocity consists of three terms: ordinary diffusion, thermal diffusion and correction diffusion velocities. Therefore:

$$
\begin{aligned}
V_{k x_{i}} & =V_{o k x_{i}}+V_{T k x_{i}}+V_{c x_{i}}, \\
k & =1,2, \ldots, K K, \quad x_{i}=r, z .
\end{aligned}
$$

Both the ordinary and thermal diffusion velocities can be obtained by the detailed multicomponent method, or the approximate mixture-average method. The former is accurate, but computationally expensive. The latter is correct asymptotically in some special cases, such as in a binary mixture, in diffusion of trace amounts of species into a nearly pure species, or systems in which all species except one move with nearly the same diffusion velocity. Since the current study concentrates on the relative influence of thermal diffusion, the ordinary diffusion velocity $V_{o k x_{i}}$, caused by concentration gradient, is obtained by the approximate mixture-average formulation (Kee et al., 1986), i.e.

$$
V_{o k x_{i}}=-\frac{1}{Y_{k}} D_{k} \frac{\partial Y_{k}}{\partial x_{i}} \quad k=1,2, \ldots, K K, \quad x_{i}=r, z .
$$

Quantity $V_{T k x_{i}}$ is the thermal diffusion velocity, whose influence will be investigated in the present paper, in $x_{i}$ ( $r$ or $z$ ) direction for the $k$ th gas species. It is obtained by the detailed multicomponent formulation (Kee et al., 1986):

$$
V_{T k x_{i}}=-\frac{D_{k}^{\mathrm{T}}}{\rho Y_{k}} \frac{1}{T} \frac{\partial T}{\partial x_{i}} \quad k=1,2, \ldots, K K, \quad x_{i}=r, z
$$

where $D_{k}^{\mathrm{T}}$ is the thermal diffusion coefficient obtained by the method given by Kee et al. (1986).

The correction diffusion velocity $V_{c x_{i}}$ is used to ensure that the net diffusive flux of all gas species and soot is zero (Kee et al., 1986).

Quantity $D_{k}$ in Eq. (7) is related to the binary diffusion coefficients through the expression:

$$
D_{k}=\frac{1-X_{k}}{\sum_{j \neq k}^{K K} \frac{X_{j}}{D_{j k}}}, \quad k=1,2, \ldots, K K
$$

where $X_{k}$ is the mole fraction of the $k$ th species, and $D_{j k}$ is the binary diffusion coefficient.

\section{Soot Model}

Although some detailed kinetic models of soot inception, growth and oxidation have been derived, such as those by Frenklach et al. (1984) and Frenklach and Wang (1990, 1994), they are too complex and computationally expensive to be implemented in simulations of multidimensional combustion systems. Conversely, the applicability of purely empirical soot models is questionable under conditions different from those under which they were originally formulated. Based on some semiempirical assumptions, McEnally et al. (1998) and Smooke et al. (1999) used the sectional model to simulate the soot formation processes. In addition to the momentum, energy and gas species conservation equations, several soot section equations (usually more than 10) need to be solved. The model developed by Leung et al. (1991) and Fairwhether et al. (1992) has been successfully used in our previous studies (Guo et al., 2002a,b) for the simulations of ethylene/air diffusion flames. It has been shown that this model can capture the features of the effects of inert species dilution on soot formation in ethylene/air diffusion flames. As only two additional equations need to be solved for soot processes in this model, it is used again in the present paper.

Two transport equations are solved for soot mass fraction and number density. They are

$$
\begin{aligned}
\rho v & \frac{\partial Y_{s}}{\partial r}+\rho u \frac{\partial Y_{s}}{\partial z} \\
& =-\frac{1}{r} \frac{\partial}{\partial r}\left(r \rho V_{T, r} Y_{s}\right)-\frac{\partial}{\partial z}\left(\rho V_{T, z} Y_{s}\right)+S_{m} \\
\rho v & \frac{\partial N}{\partial r}+\rho u \frac{\partial N}{\partial z} \\
& =-\frac{1}{r} \frac{\partial}{\partial r}\left(r \rho V_{T, r} N\right)-\frac{\partial}{\partial z}\left(\rho V_{T, z} N\right)+S_{N}
\end{aligned}
$$

where $Y_{\mathrm{s}}$ is the soot mass fraction, $N$ is the soot number density defined as the particle number per unit mass of mixture. Quantities $V_{\mathrm{T}, r}$ and $V_{\mathrm{T}, z}$ are the particle thermophoretic velocities. They are obtained by the expression for a free molecular aerosol 
(Talbot et al., 1980):

$$
V_{T, x_{i}}=-0.55 \frac{\mu}{\rho T} \frac{\partial T}{\partial x_{i}} \quad x_{i}=r, z .
$$

Although the particle thermophoretic motion is also a kind of thermal diffusion, its effect was not studied in this paper, since the emphasis in this paper is the thermal diffusion of gas species (Eq. 8).

The source term $S_{m}$ in Eq. (10) accounts for the contributions of soot nucleation $\left(\omega_{n}\right)$, surface growth $\left(\omega_{g}\right)$ and oxidation $\left(\omega_{O}\right)$. Therefore,

$$
S_{m}=\omega_{n}+\omega_{g}-\omega_{O}
$$

The model developed by Leung et al. (1991) and Fairwhether et al. (1992) is used to obtain the three terms on the right-hand side of Eq. (13). The model assumes the chemical reactions for nucleation and surface growth, respectively, as:

$$
\begin{aligned}
& \mathrm{C}_{2} \mathrm{H}_{2} \rightarrow 2 \mathrm{C}(\mathrm{S})+\mathrm{H}_{2} \\
& \mathrm{C}_{2} \mathrm{H}_{2}+n \mathrm{C}(\mathrm{S}) \rightarrow(n+2) \mathrm{C}(\mathrm{S})+\mathrm{H}_{2}
\end{aligned}
$$

with the reaction rates given by the expressions:

$$
\begin{aligned}
& r_{1}=k_{1}(T)\left[\mathrm{C}_{2} \mathrm{H}_{2}\right] \\
& r_{2}=k_{2}(T) f\left(A_{\mathrm{s}}\right)\left[\mathrm{C}_{2} \mathrm{H}_{2}\right]
\end{aligned}
$$

where $f\left(A_{\mathrm{s}}\right)$ denotes the functional dependence on soot surface area per unit volume. Similar to our previous studies (Guo et al., 2002a,b), a simple linear functional dependence is used, i.e. $f\left(A_{\mathrm{s}}\right)=A_{\mathrm{s}}$.

Neoh et al. (1981) investigated the soot oxidation process in flames, and found that the oxidation due to both $\mathrm{O}_{2}$ and $\mathrm{OH}$ is important, depending on the local equivalence ratio. The radical $\mathrm{O}$ also contributes to soot oxidation in some regions. Therefore the soot oxidation by $\mathrm{O}_{2}, \mathrm{OH}$ and $\mathrm{O}$ are accounted for by the following reactions:

$$
\begin{aligned}
& 0.5 \mathrm{O}_{2}+\mathrm{C}(\mathrm{S}) \rightarrow \mathrm{CO} \\
& \mathrm{OH}+\mathrm{C}(\mathrm{S}) \rightarrow \mathrm{CO}+\mathrm{H} \\
& \mathrm{O}+\mathrm{C}(\mathrm{S}) \rightarrow \mathrm{CO} .
\end{aligned}
$$

The reaction rates for these three reactions were obtained by:

$$
\begin{aligned}
& r_{3}=k_{3}(T) T^{1 / 2} A_{s}\left[\mathrm{O}_{2}\right] \\
& r_{4}=\varphi_{\mathrm{OH}} k_{4}(T) T^{-1 / 2} A_{s} X_{\mathrm{OH}} \\
& r_{5}=\varphi_{\mathrm{O}} k_{5}(T) T^{-1 / 2} A_{s} X_{\mathrm{O}}
\end{aligned}
$$

where $X_{\mathrm{OH}}$ and $X_{\mathrm{O}}$ denote the mole fractions of $\mathrm{OH}$ and $\mathrm{O}$, and $\varphi_{\mathrm{OH}}$ and $\varphi_{\mathrm{O}}$ are the collision efficiencies for
TABLE I Rate constants, as $k_{i}=A \exp (-E / R T$ ) (units are $\mathrm{kg}, \mathrm{m}, \mathrm{s}$, kcal, kmol and K)

\begin{tabular}{lccl}
\hline$k_{\mathrm{i}}$ & $\mathrm{A}$ & $\mathrm{E}$ & \multicolumn{1}{c}{ Reference } \\
\hline$k_{1}$ & $1.35 \mathrm{E}+06$ & 41 & Fairwhether et al. (1992) \\
$k_{2}$ & $5.00 \mathrm{E}+02$ & 24 & Fairwhether et al. (1992) \\
$k_{3}$ & $1.78 \mathrm{E}+04$ & 39 & Fairwhether et al. (1992) \\
$k_{4}$ & $1.06 \mathrm{E}+02$ & 0 & Neoh et al. $(1981)$ \\
$k_{5}$ & $5.54 \mathrm{E}+01$ & 0 & Bradley et al. $(1984)$ \\
\hline
\end{tabular}

$\mathrm{OH}$ and $\mathrm{O}$ attack on soot particles, respectively. The collision efficiency of $\mathrm{OH}$ is treated as that described by Kennedy et al. (1996), who accounted for the variation of the collision efficiency of $\mathrm{OH}$ with time by assuming a linear relation between the collision efficiency and a dimensionless distance from the fuel nozzle exit. A collision efficiency of 0.5 for radical $\mathrm{O}$ attack on the particles is used in this study (Bradley et al., 1984).

All the reaction rate constants, $k_{i}(i=1, \ldots, 5)$, are summarized in Table I.

The source term $S_{N}$ in Eq. (11) accounts for the soot nucleation and agglomeration, and is calculated as:

$$
\begin{aligned}
S_{N}= & \frac{2}{C_{\min }} N_{\mathrm{A}} r_{1}-2 C_{a}\left(\frac{6 M_{C(S)}}{\pi \rho_{C(S)}}\right)^{1 / 6} \\
& \times\left(\frac{6 \kappa T}{\rho_{C(S)}}\right)^{1 / 2}[C(s)]^{1 / 6}[\rho N]^{11 / 6}
\end{aligned}
$$

where $N_{\mathrm{A}}$ is Avogadro's number $\left(6.022 \times 10^{26}\right.$ particles $/ \mathrm{kmol}), C_{\min }$ is the number of carbon atoms in the incipient carbon particle $\left(9 \times 10^{4}\right)$ (Fairwhether et al., 1992), $\kappa$ is the Boltzman constant $\left(1.38 \times 10^{-23} \mathrm{~J} / \mathrm{K}\right)$, $\rho_{C(S)}$ is the soot density $\left(1800 \mathrm{~kg} / \mathrm{m}^{3}\right), C(\mathrm{~s})$ is the mole concentration of soot $\left(\mathrm{kmol} / \mathrm{m}^{3}\right), M_{C(\mathrm{~s})}$ is the molar mass of soot $(12.011 \mathrm{~kg} / \mathrm{kmol})$, and $C_{a}$ is the agglomeration rate constant for which a value of 3.0 (Fairwhether et al., 1992) is used.

\section{Numerical Scheme}

The flames modeled in this study are generated with a burner (Gülder et al., 1996) in which the fuel stream flows from a $10.9 \mathrm{~mm}$ inner diameter vertical tube, and the oxidant stream flows from the annular region between the fuel tube and a $100 \mathrm{~mm}$ inner diameter concentric tube. The wall thickness of the fuel tube is $0.95 \mathrm{~mm}$.

The computational domain covers an area from 0 to $3.0 \mathrm{~cm}$ in the radial direction and 0 to $11.0 \mathrm{~cm}$ in the axial direction. The inflow boundary $(z=0 \mathrm{~cm})$ corresponds to the region immediately above the fuel nozzle exit. This computational domain has been shown to be large enough by a sensitivity calculation. Totally, $104 \times 71$ non-uniform grids are used. Finer grids are placed in the reaction zone and near the fuel nozzle exit region by a grid adaptive refinement method. 

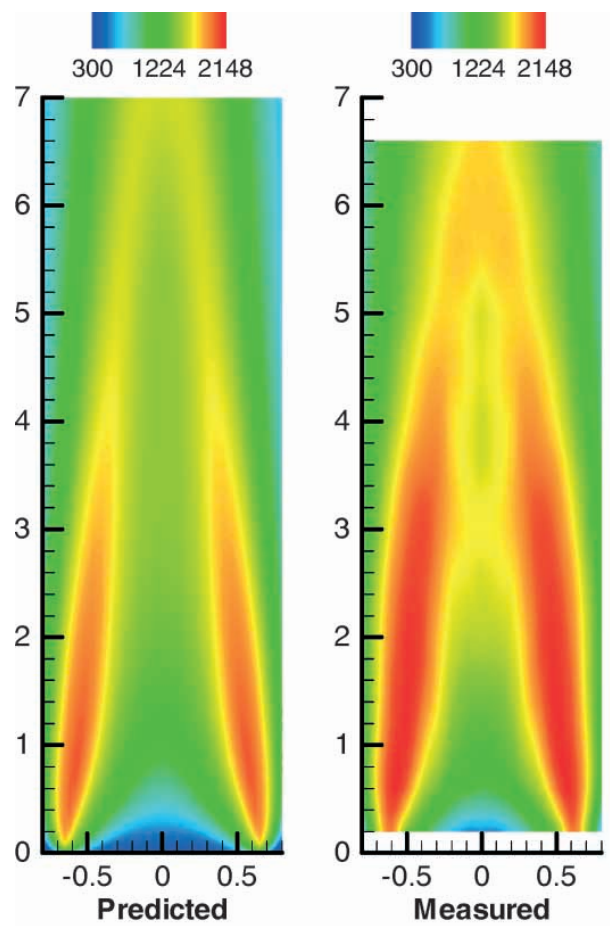

Temperature, $\mathbf{K}$
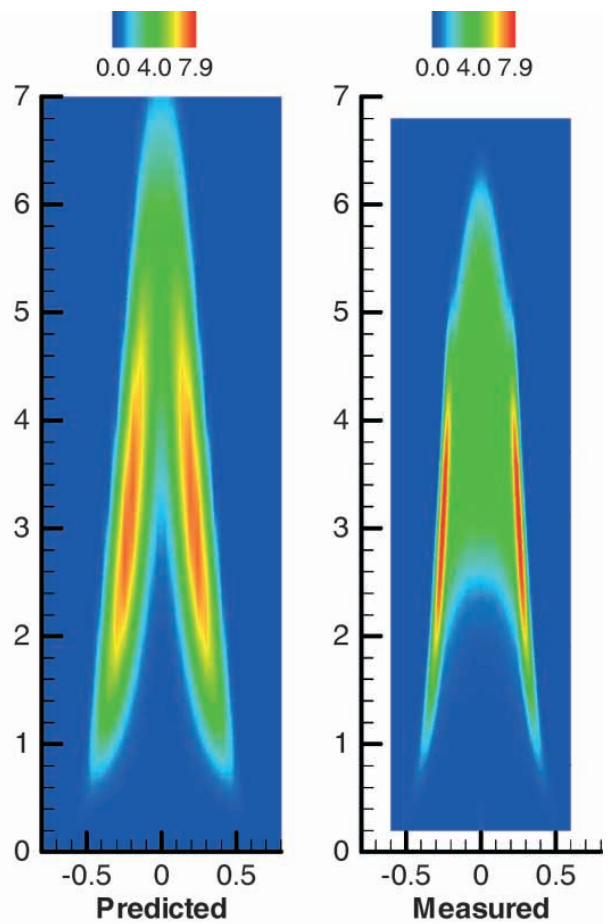

Soot volume fraction, $\mathrm{ppm}$

FIGURE 1 Comparison of predicted and measured flame temperature and soot volume fraction
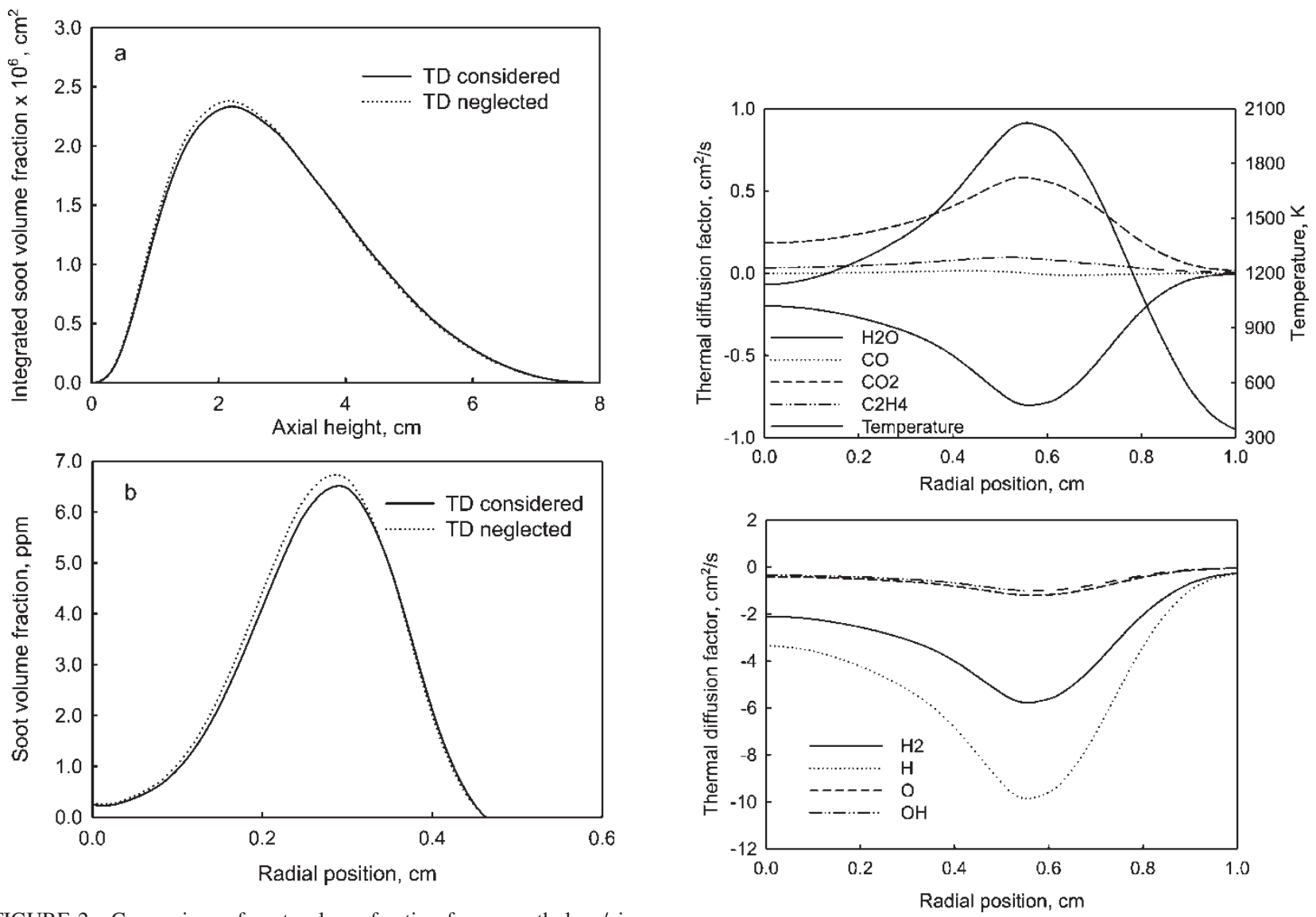

FIGURE 2 Comparison of soot volume fraction for pure ethylene/air flame. a. Integrated soot volume fraction; b. Radial soot volume fraction at axial height of $z=1.0 \mathrm{~cm}$. TD represents Thermal Diffusion.

FIGURE 3 Thermal diffusion factors of some main species and radicals at the axial height of $z=1.0 \mathrm{~cm}$ for pure ethylene/air flame. 

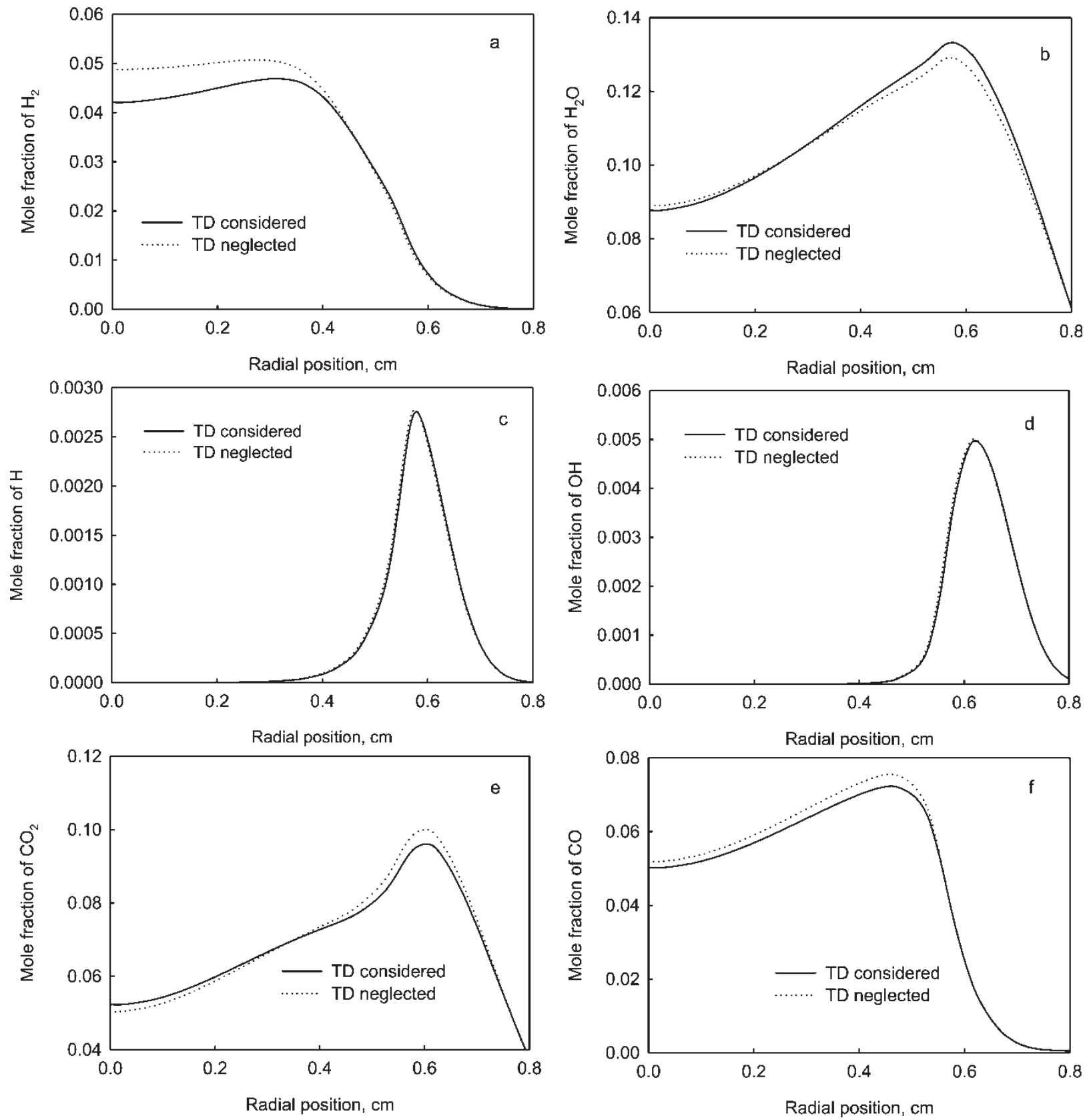

FIGURE 4 Radial profiles of $\mathrm{H}_{2} \mathrm{O}, \mathrm{H}_{2}, \mathrm{H}, \mathrm{OH}, \mathrm{CO}_{2}$ and $\mathrm{CO}$ at axial height of $z=1.0 \mathrm{~cm}$ for pure ethylene/air flame. TD represents Thermal Diffusion

It has been checked that the further increase of grid number does not significantly influence the simulation results.

At the inlet, the velocity and temperature profiles are obtained by the simulation in our previous study (Guo et al., 2002b) to account for the flame preheating effect, and the concentrations of species are specified as the given values in fuel and oxidant streams. The symmetric condition is used for the axis. For the outer boundary, the free slip condition is used for velocities, and the concentrations of species are specified as those in the oxidant stream. The zero gradient condition is used for the exit boundary.
The governing equations are discretized using the control volume method. The SIMPLE numerical scheme (Patankar, 1980) is used to deal with the pressure and velocity coupling. The diffusion and convective terms in the conservation equations are discretized by the central and the first-order upwind difference methods, respectively. The discretized equations of gas species, soot mass fraction and soot number density are solved in a fully coupled fashion on every grid (Liu et al., 1995) to speed up the convergence process, while those of momentum, energy and pressure correction are solved using the tri-diagonal matrix algorithm. 


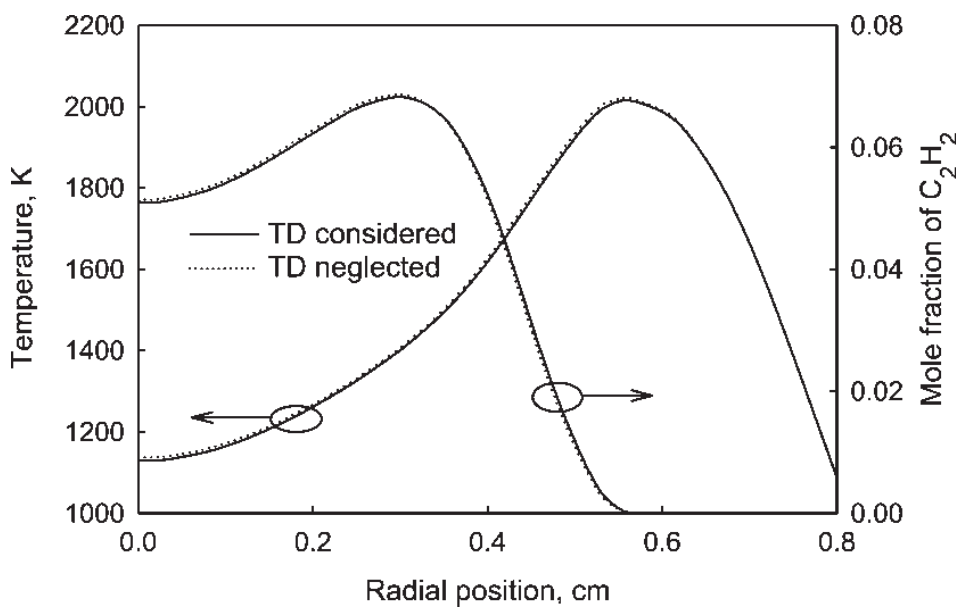

FIGURE 5 Radial profiles of temperature and mole fraction of acetylene $\left(\mathrm{C}_{2} \mathrm{H}_{2}\right)$ at $z=1.0 \mathrm{~cm}$ for pure ethylene/air flame. TD represents Thermal Diffusion.

The chemical reaction mechanism used is essentially from GRI-Mech 3.0 (Smith et al., 1999), with the removal of all the reactions and species related to $\mathrm{NO}_{\mathrm{X}}$ formation. The revised reaction scheme consists of 37 species and 219 reactions. All the thermal and transport properties are obtained by using the database of GRI-Mech 3.0 and the algorithms given in Kee et al. (1986, 1980).

\section{RESULTS AND DISCUSSIONS}

Five flames in total are studied. They are pure ethylene/air flame, and the flames with $30 \%$ helium addition to the fuel, $30 \%$ helium addition to the air, $30 \%$ argon addition to the fuel and 30\% argon addition to the air. The volume flow rates of fuel (ethylene) and air are the same for all the five flames, while helium or argon is added to the fuel or air stream in the second to fifth flames.
For each flame, two simulations, one with thermal diffusion and the other without thermal diffusion, are conducted. Since the emphasis of this paper is on the effects of thermal diffusion of various gas species, the soot particle thermophoresis (Eq. 12) is included in all the simulations.

\section{Pure Ethylene/Air Flame}

In order to validate the combustion and soot model, we first compare the simulated flame temperature and soot volume fraction with those experimentally obtained (Gülder et al., 1996) for a pure ethylene/air flame, as shown in Fig. 1. The simulation results in Fig. 1 are obtained when thermal diffusion is taken into account. It demonstrates that the simulation captures the general features of the flame, i.e. the temperature profiles have a maximum in the annular region of the lower part of the flame, and these maximum temperature contours do not

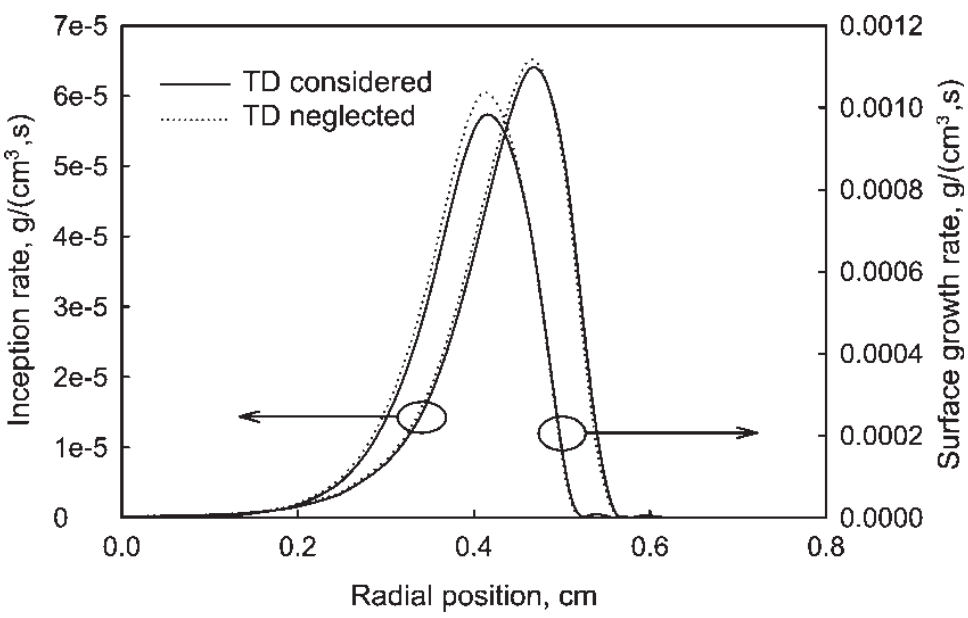

FIGURE 6 Inception and surface growth rates of pure ethylene/air flame at $z=1.0 \mathrm{~cm}$. TD represents Thermal Diffusion. 


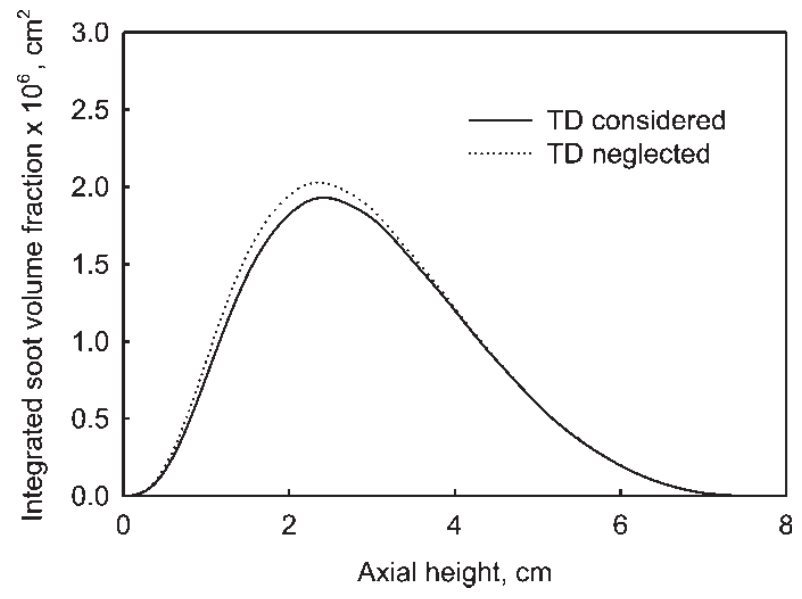

FIGURE 7 The comparison of integrated soot volume fraction of the flame with $30 \% \mathrm{He}$ addition to the fuel. TD represents Thermal Diffusion.

converge to the axis in the upper part of the flame. The predicted soot volume fraction distribution is close to that obtained experimentally. The discrepancies between the simulated and measured soot volume fraction may be attributed to the simplification of the soot model and the reaction scheme used.

The influence of thermal diffusion on the prediction of soot formation in a pure ethylene/air flame is now investigated by comparing the results of simulations with and without thermal diffusion. Figure 2 depicts the integrated soot volume fraction, obtained by integrating the soot volume fraction with respect to the section area, and radial soot volume fraction profile at $z=1.0 \mathrm{~cm}$ for the pure ethylene/air flame. It is observed that thermal diffusion does affect the prediction of soot formation, although the difference in this case is not significant. The soot volume fraction is greater when thermal diffusion is neglected. The peak integrated soot volume fraction is about $2.1 \%$ higher if thermal diffusion is not taken into account.

Thermal diffusion causes variations in the distributions of main species and radicals in the flame. Figure 3 shows the thermal diffusion factors, defined as the ratio of thermal diffusion coefficient $\left(D_{k}^{\mathrm{T}}\right)$ to the product of mixture density and species mass fraction $\left(\rho Y_{k}\right)$, of several main species and radicals at $z=1.0 \mathrm{~cm}$. The radial temperature profile at $z=1.0 \mathrm{~cm}$ is also shown for reference. It indicates that the thermal diffusion factors of species $\mathrm{H}_{2} \mathrm{O}, \mathrm{H}_{2}, \mathrm{H}, \mathrm{O}$ and $\mathrm{OH}$ are negative, while those of $\mathrm{CO}_{2}$ and $\mathrm{C}_{2} \mathrm{H}_{4}$ are positive. Therefore thermal diffusion tends to draw the lighter species, such as $\mathrm{H}_{2} \mathrm{O}, \mathrm{H}_{2}$ and $\mathrm{H}$, to the hotter region and to drive the heavier species, such as $\mathrm{CO}_{2}$, to the colder region, as shown in Fig. 4. Although the thermal diffusion factors of radical $\mathrm{OH}$ are negative, its concentrations in the hotter region are actually lower when thermal diffusion is taken into account (Fig. 4d) due to the nonlinear coupling effect of chemical reaction. Similarly, the concentrations of $\mathrm{CO}$ in the centreline region are lower when thermal diffusion is taken into account (Fig. 4f) in spite of its near-zero thermal diffusion factor (Fig. 3).

These variations of chemical species concentrations introduce the disparities in the flame temperatures, and thus finally cause the discrepancies of soot inception and surface growth process. Figure 5 demonstrates the radial profiles of temperature and acetylene $\left(\mathrm{C}_{2} \mathrm{H}_{2}\right)$ mole fraction for the simulations with and without thermal diffusion. If thermal diffusion is not taken into account, the concentrations of acetylene, which is the main precursor of soot, are higher in the central region and lower outside the peak value position. However, the temperatures are higher in the reaction zone and the centreline region if thermal diffusion is neglected. As a result, both inception and surface growth rates are higher at and inside the peak inception

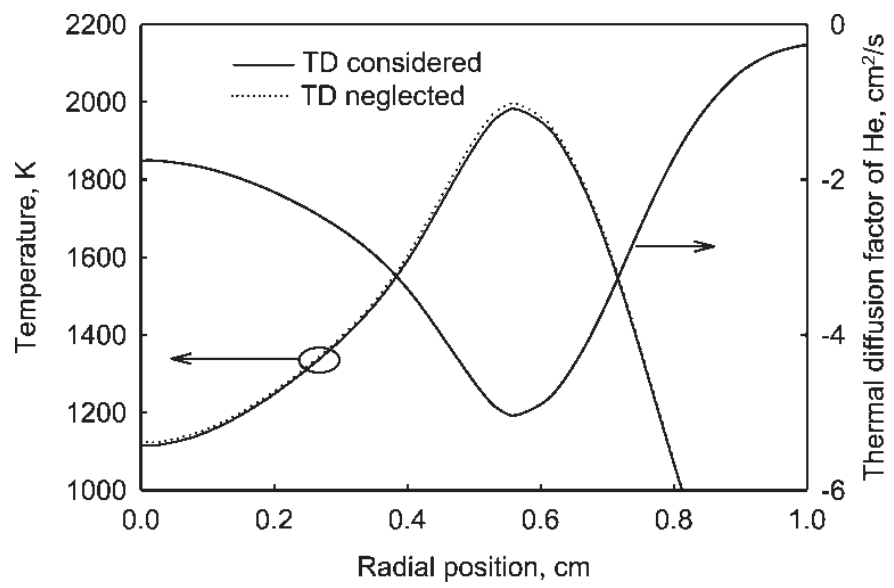

FIGURE 8 Radial profiles of temperature and thermal diffusion factor of $\mathrm{He}$ at $z=1.0 \mathrm{~cm}$ for the flame with $30 \%$ He added to the fuel. TD represents Thermal Diffusion. 


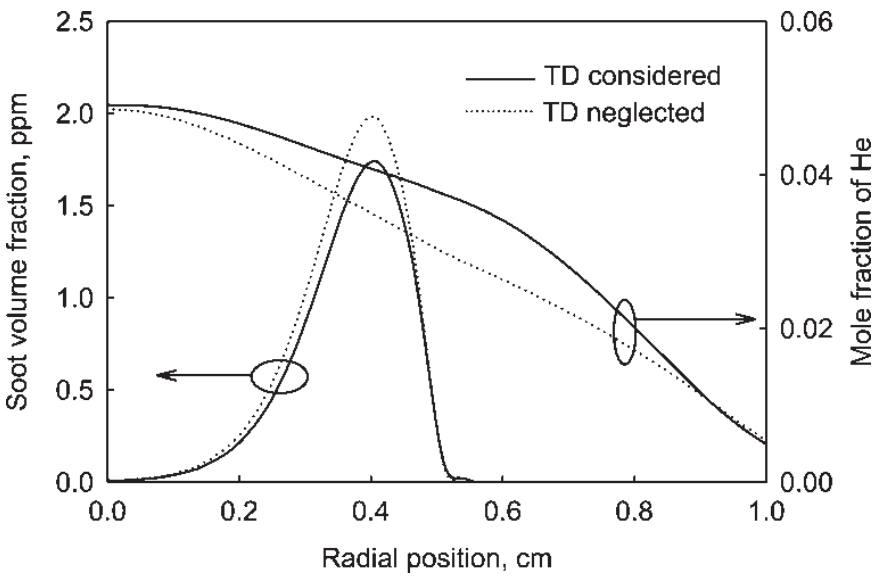

FIGURE 9 Radial profiles of He mole fraction and soot volume fraction at $z=1.0 \mathrm{~cm}$ for the flame with $30 \%$ He added to fuel. TD represents Thermal Diffusion.

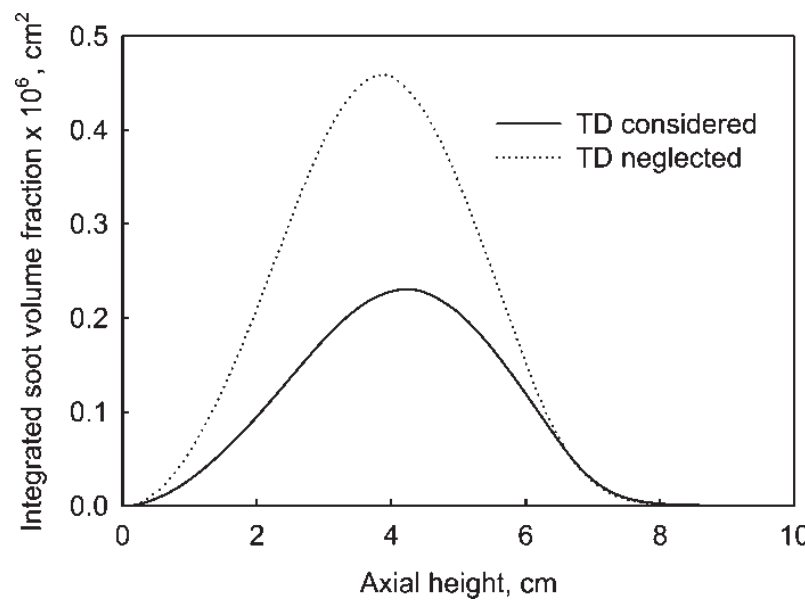

FIGURE 10 The comparison of integrated soot volume fraction of the flame with $30 \%$ He addition to the air. TD represents Thermal Diffusion.

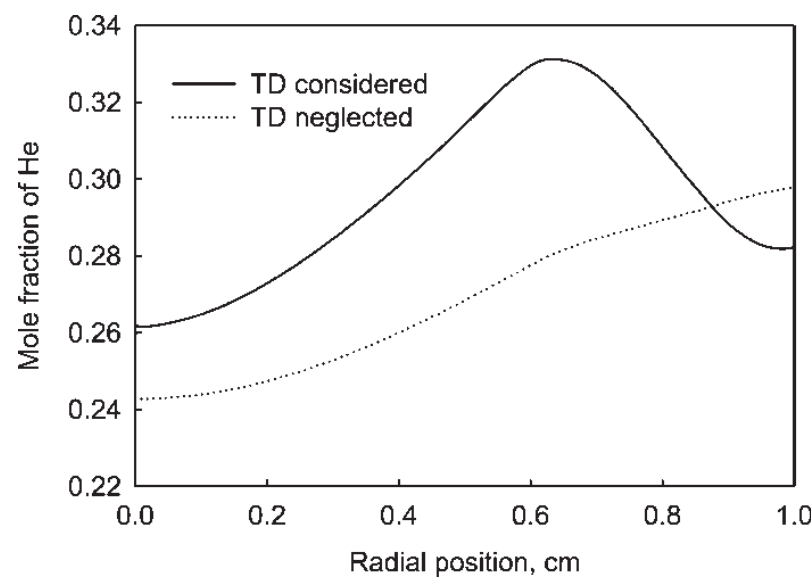

FIGURE 11 Radial profile of He mole fraction at $z=1.0 \mathrm{~cm}$ for the flame with $30 \% \mathrm{He}$ addition to the air. TD represents Thermal Diffusion. and growth rate positions and the situation reverses in the outside region if thermal diffusion is neglected, as shown in Fig. 6. Accordingly, the soot volume fraction is higher at and inside the peak concentration position region for the simulation without thermal diffusion (Fig. 2b). Since peak inception and surface growth occur in the region between the positions with peak acetylene concentration and peak temperature, where the concentrations of acetylene without thermal diffusion are lower than those with thermal diffusion, this result also implies that temperature dominates soot inception and surface growth processes.

The situations at other axial heights are similar to that at $z=1.0 \mathrm{~cm}$. Therefore the integrated soot volume fractions are greater when thermal diffusion is not taken into account.

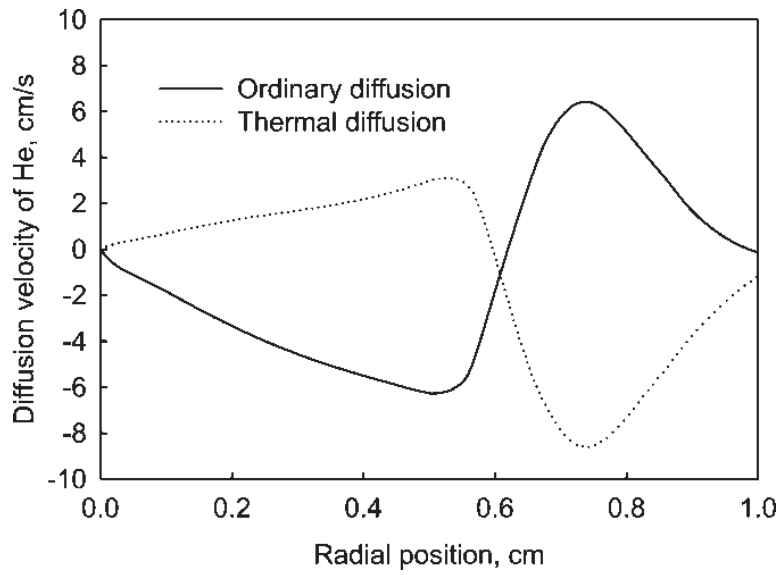

FIGURE 12 Ordinary and thermal diffusion velocity of helium at $z=1.0 \mathrm{~cm}$ for the flame with $30 \% \mathrm{He}$ addition to the air. 


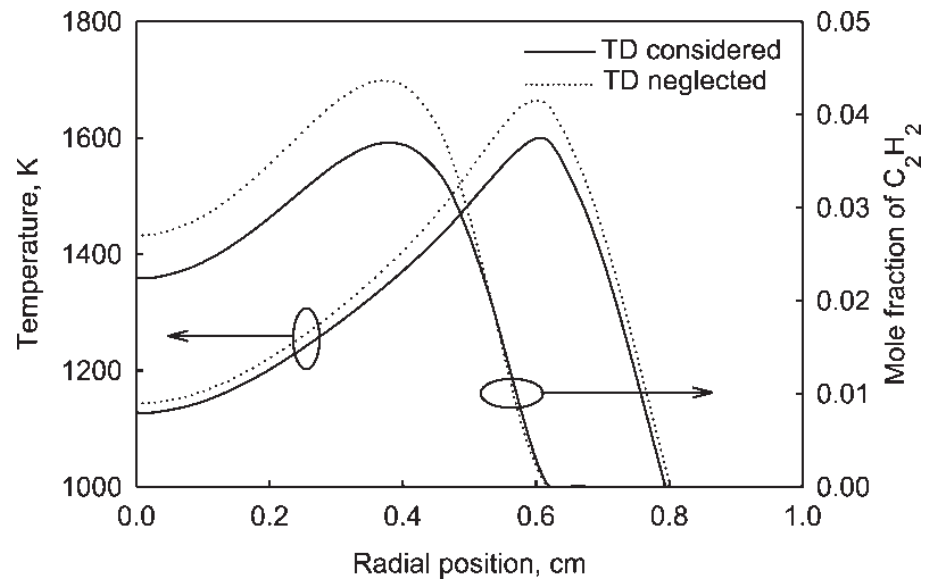

FIGURE 13 The temperature and mole fraction of $\mathrm{C}_{2} \mathrm{H}_{2}$ at $z=1.0 \mathrm{~cm}$ for the flame with $30 \% \mathrm{He}$ addition to the air. TD represents Thermal Diffusion.

\section{Flame with 30\% Helium Addition to Fuel}

Various inert diluents have been used to investigate the influences of their addition to the fuel or air stream on soot formation in laminar diffusion flames. Helium and argon are two typical examples of such diluents. The influence of thermal diffusion on soot formation in helium and argon diluted ethylene/air flames is investigated below.

Figure 7 compares the integrated soot volume fractions of the simulations with and without thermal diffusion for the flame with $30 \%$ helium addition to the fuel. Similar to the pure ethylene/air flame, the soot volume fraction is higher when thermal diffusion is neglected. However, the influence is increased compared to the pure ethylene/air flame. The peak integrated soot volume fraction is 5.0\% higher for this flame if thermal diffusion is not taken into account.

In addition to those variations caused by thermal diffusion for a pure ethylene/air flame, helium is driven to the reaction (hot) zone due to its negative thermal diffusion factors in this flame, as shown in Figs. 8 and 9.
Therefore the variations of temperature in the reaction zone caused by thermal diffusion are further increased, due to the addition of helium to the fuel. Consequently, the influence of thermal diffusion on soot formation is greater in this flame than in the pure ethylene/air flame.

\section{Flame with 30\% Helium Addition to Air}

Figure 10 shows the influence of thermal diffusion on the integrated soot volume fraction of the flame with $30 \%$ helium addition to air. The thermal diffusion effect becomes very significant for this flame. The peak integrated soot volume fraction doubles if thermal diffusion is neglected in the simulation. Again this is due to the migration of helium to the hot region caused by thermal diffusion.

As indicated above, thermal diffusion factors of helium are negative and thus helium is driven to the hot region of the flame. Figure 11 shows that the concentration of helium in the reaction (hot) zone for the simulation with thermal

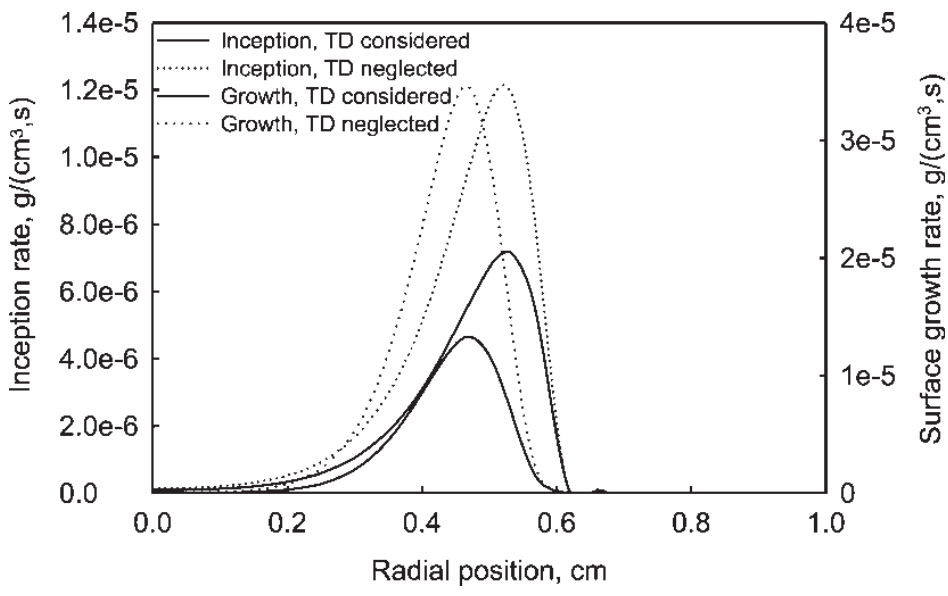

FIGURE 14 Inception and surface growth rates at $z=1.0 \mathrm{~cm}$ for the flame with $30 \% \mathrm{He}$ addition to the air. TD represents Thermal Diffusion. 


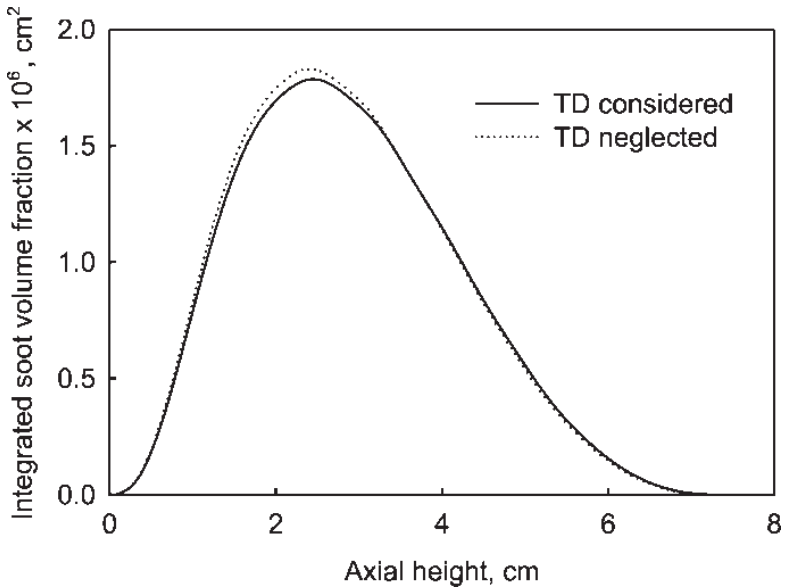

FIGURE 15 Integrated soot volume fraction for the flame with $30 \% \mathrm{Ar}$ addition to the fuel. TD represents Thermal Diffusion.

diffusion is much higher than that of the simulation without thermal diffusion. A more interesting phenomenon here is that the concentration of helium in the reaction zone is even higher than those in the periphery region. Since helium is added to the air stream, this phenomenon implies that the thermal diffusion velocities of helium exceed the ordinary diffusion velocities, caused by concentration gradient, around the reaction zone. This is clearly shown in Fig. 12.

The higher helium concentration in the reaction zone for the simulation with thermal diffusion results in much lower temperatures and lower acetylene concentrations in most parts of the reaction zone, as shown in Fig. 13. As a result, both inception and surface growth rates of the simulation with thermal diffusion are much lower than those of the simulation without thermal diffusion (Fig. 14). Therefore,

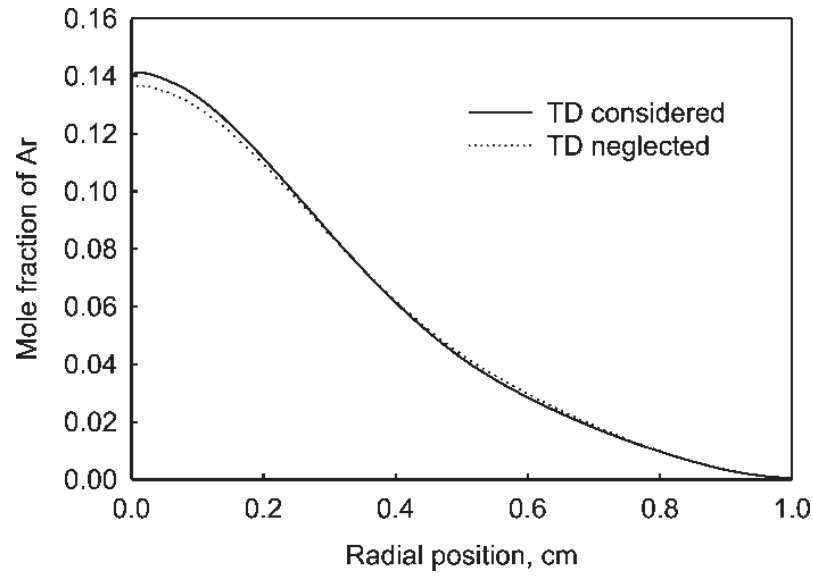

FIGURE 17 Mole fraction of $\mathrm{Ar}$ at $z=1.0 \mathrm{~cm}$ for the flame with $30 \%$ Ar addition to the air. TD represents Thermal Diffusion.

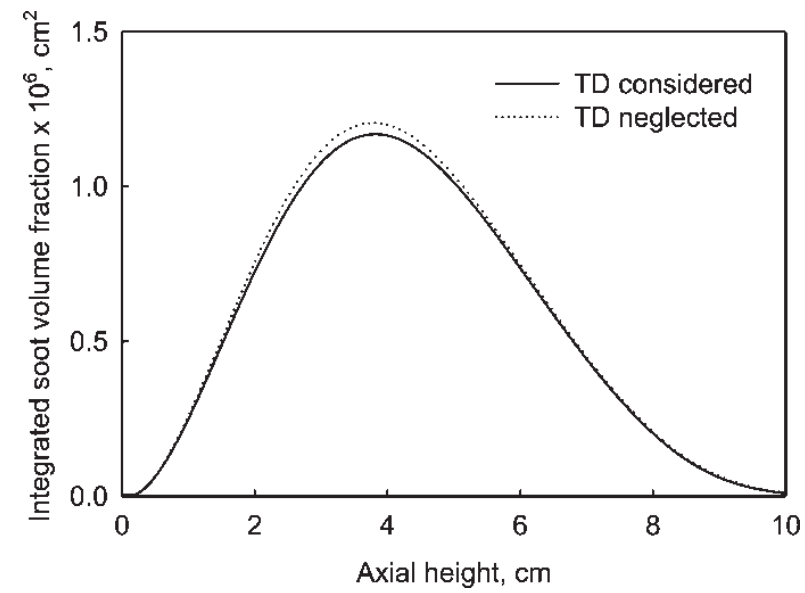

FIGURE 18 Integrated soot volume fraction for the flame with 30\% $\mathrm{Ar}$ addition to the air. TD represents Thermal Diffusion.

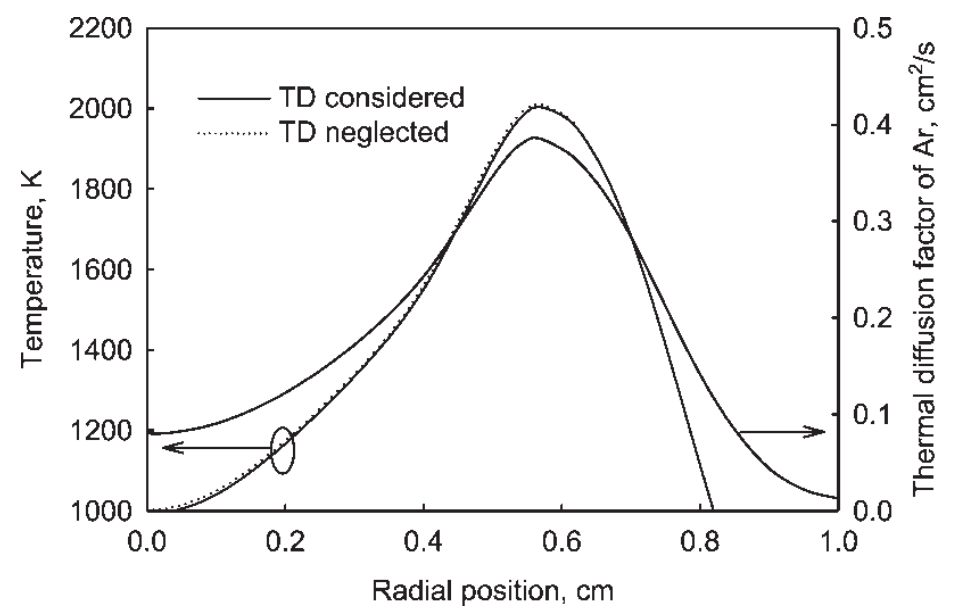

FIGURE 16 Radial profiles of temperature and thermal diffusion factor of $\mathrm{Ar}$ at $z=1.0 \mathrm{~cm}$ for the flame with $30 \%$ Ar addition to the fuel. TD represents Thermal Diffusion. 


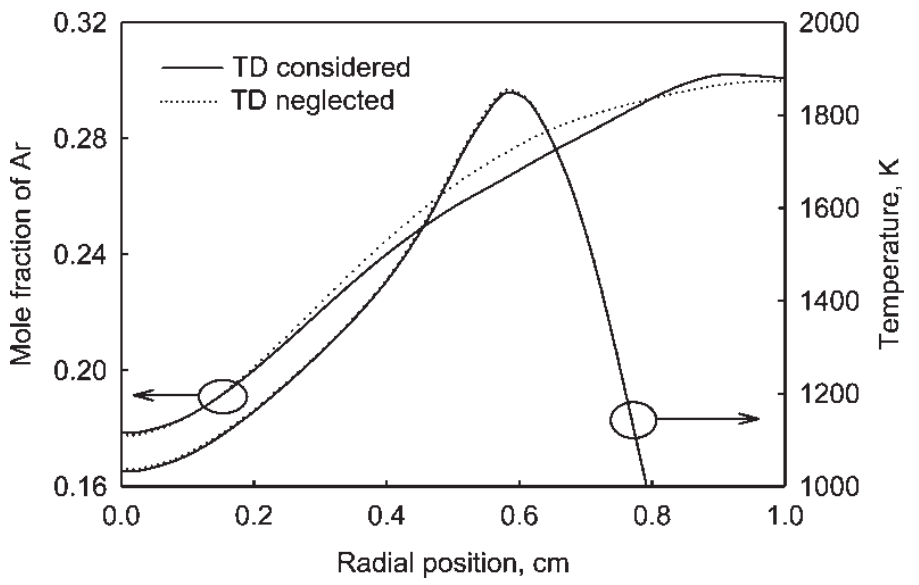

FIGURE 19 Radial profiles of argon mole fraction and temperature at $z=1.0 \mathrm{~cm}$ for the flame with $30 \%$ Ar addition to the air. TD represents Thermal Diffusion.

we can conclude that thermal diffusion has a significant effect on soot formation processes in helium diluted ethylene/air diffusion flame, and thus should be taken into account in the numerical simulation.

\section{Flame with 30\% Argon Addition to Fuel}

Argon is another inert gas species that is usually used as a diluent to be added to flames to reduce soot formation. Figure 15 depicts the influence of thermal diffusion on the integrated soot volume fraction for the flame with $30 \%$ argon addition to the fuel. It reveals that the influence of thermal diffusion on soot formation in this flame is similar to that in the pure ethylene/air flame. The peak integrated soot volume fraction is $2.4 \%$ higher when thermal diffusion is neglected.

Thermal diffusion factors of argon are very small, with a peak value less than 0.5 , as shown in Fig. 16. Figure 17 shows the radial profiles of argon at $z=1.0 \mathrm{~cm}$. It reveals that although argon is driven to the cold region due to the positive thermal diffusion factor, this effect is very small. Therefore the concentration of argon in the reaction zone of the simulation with thermal diffusion is only slightly lower than that of the simulation without thermal diffusion. The influence of thermal diffusion on soot formation in this flame is mainly caused by the variations of concentrations of other species, such as those discussed for the pure ethylene/air flame.

\section{Flame with 30\% Argon Addition to Air}

The integrated soot volume fraction of the flame with $30 \%$ argon addition to the air is plotted in Fig. 18. Again the soot volume fraction is higher when thermal diffusion is neglected. The peak integrated soot volume fraction of the simulation without thermal diffusion is about 3.3\% higher.

Similar to the addition of argon to the fuel, although the concentration of argon in the reaction zone is raised, the temperature is still higher when thermal diffusion is not accounted for, as shown in Fig. 19. This is because the magnitude of the thermal diffusion factor of argon is not positively large enough and thus the difference of argon concentrations in the reaction zone of the simulations with and without thermal diffusion is very small. The migration of other species caused by thermal diffusion and the nonlinear coupling effect causes higher temperatures in the reaction zone when thermal diffusion is neglected. Therefore the soot volume fraction is higher if thermal diffusion is neglected in the simulation of this flame.

\section{CONCLUSIONS}

The influence of thermal diffusion on soot formation in coflow laminar ethylene/air and argon or helium diluted ethylene/air diffusion flames has been numerically investigated. The results show that thermal diffusion, caused by temperature gradient, does affect the prediction of soot formation in these flames. Although the influence of thermal diffusion on soot formation is not significant for the pure ethylene/air and argon diluted ethylene/air diffusion flames, it becomes significant for helium diluted ethylene/air diffusion flames. In particular, when helium is added to the air stream, the peak integrated soot volume fraction can double if thermal diffusion is not taken into account. The thermal diffusion velocity of helium in the flame can exceed the ordinary diffusion velocity. Therefore, it is necessary to consider the effect of thermal diffusion in the modeling of soot formation in ethylene/air diffusion flames.

\section{References}

Axelbaum, R.L. and Law, C.K. (1990) "Soot formation and inert addition in diffusion flames", Twenty-third Symposium (Int.) on Combustion (The Combustion Institute, Pittsburgh, USA), pp 1517-1523.

Axelbaum, R.L., Law, C.K. and Flower, W.L. (1988) "Preferential diffusion and concentration modification in sooting counterflow diffusion flames", Twenty-second Symposium (Int.) on Combustion (The Combustion Institute, Pittsburgh, USA), pp 379-386. 
Bennett, B.A., McEnally, C.S., Pfefferle, L.D. and Smooke, M.D. (2001) "Computational and experimental study of axisymmetric coflow partially premixed ethylene/air flames", Combustion and Flame 127, 2004-2022.

Bradley, D., Dixon-Lewis, G., Habik, S.E. and Mushi, E.M. (1984) “The oxidation of graphite powder in flame reaction zones", Twentieth Symposium (Int.) on Combustion (The Combustion Institute, Pittsburgh, USA), pp 931-940.

Chase, M.W., Davies, C.A., Downey, J.R., Frurlp, D.J., McDonald, R.A. and Syverud, A.N. (1985) JANAF Thermochemical Tables, 3rd Ed. (American Chemical Society and American Institute of Physics, New York)

Dalzell, W.H. and Sarofim, A.F. (1969) "Optical constants of soot and their application to heat-flux calculations", Journal of Heat Transfer 91, 100-104.

Dixon-Lewis, G. (1968) "Flame structure and flame reaction kinetics", Proc. Royal Soc. London A307, 111-135.

Ern, A. and Giovangigli, V. (1998) "Thermal diffusion effects in hydrogen-air and methane-air flames", Combustion Theory and Modelling 2, 349-372.

Ern, A. and Giovangigli, V. (1999) "Impact of detailed multicomponent transport on planar and counterflow hydrogen/air and methane/air flames", Combustion Science and Technology 149, 157-181.

Fairwhether, M., Jones, W.P. and Lindstedt, R.P. (1992) "Predictions of radiative transfer from a turbulent reacting jet in a cross-wind", Combustion and Flame 89, 45-63.

Frenklach, M. and Wang, H. (1990) "Detailed modeling of soot particle nucleation and growth", Twenty-third Symposium (Int.) on Combustion (The Combustion Institute, Pittsburgh, USA), pp $1559-1566$

Frenklach, M. and Wang, H. (1994) "Detailed mechanism and modeling of soot particle formation", In: Bockhorn, H., ed, Soot Formation in Combustion: Mechanisms and Models (Springer Series in Chemical Physics, Berlin) 59, pp 164-190.

Frenklach, M., Clary, D.W., Gardiner, W.C. and Stein, S.E. (1984) "Detailed kinetic modeling of soot formation in shock-tube pyrolysis of acetylene", Twentieth Symposium (Int.) on Combustion (The Combustion Institute, Pittsburgh, USA), pp 887-901.

Glassman, I. (1998) "Sooting laminar diffusion flames: effect of dilution, additives, pressure, and microgravity", Twenty-seventh Symposium (Int.) on Combustion (The Combustion Institute, Pittsburgh, USA), pp $1589-1596$.

Greenberg, J.B. (1980) "On the prediction of thermal diffusion effects in laminar one-dimensional flames", Combustion Science and Technology 24, 83-88.

Gülder, Ö.L., Snelling, D.R. and Sawchuk, R.A. (1996) "Influence of hydrogen addition to fuel on temperature field and soot formation in diffusion flames", Twenty-sixth Symposium (Int.) on Combustion (The Combustion Institute, Pittsburgh, USA), pp 2351-2358.

Guo, H., Liu. F., Smallwood, G.J. and Gülder, Ö.L (2002a) "A numerical study of the influence of transport properties of inert diluents on soot formation in a coflow laminar ethylene-air diffusion flame", Proceedings of Combustion Institute 29, pp 2359-2365.

Guo, H., Liu, F., Smallwood, G.J. and Gülder, Ö.L. (2002b) "The flame preheating effect on numerical modeling of soot formation in a two dimensional laminar ethylene-air diffusion flame", Combustion Theory and Modelling 6, 173-187.

Hancock, R.D., Schauer, F.R., Lucht, R.P., Katta, V.R. and Hsu, K.Y. (1996) "Thermal diffusion effects and vortex-flame interactions in hydrogen jet diffusion flames", Twenty-sixth Symposium (Int.) on Combustion (The Combustion Institute, Pittsburgh, USA), pp 1087-1093.

Kee, R.J., Miller, J.A. and Jefferson, T.H. (1980) A general-purpose, problem-independent, transportable, Fortran chemical kinetics code package (Los Alamos, USA), Sandia Report, SAND 80-8003.

Kee, R.J., Dixon-Lewis, G., Warnatz, J., Coltrin, M.E. and Miller, J.A. (1986) A Fortran computer code package for the evaluation of gas-phase, multicomponent transport properties (Los Alamos, USA), Sandia Report, SAND 86-8246.

Kennedy, I.M., Yam, C., Rapp, D.C. and Santoro, R.J. (1996) "Modeling and measurements of soot and species in a laminar diffusion flame", Combustion and Flame 107, 368-382.

Kuo, K.K. (1986) Principles of Combustion (John Wiley \& Sons, New York)

Leung, K.M., Lindstedt, R.P. and Jones, W.P. (1991) "A simplified reaction mechanism for soot formation in nonpremixed flames", Combustion and Flame 87, 289-305.

Liu, Z., Liao, C., Liu, C. and McCormick, S. (1995) Multigrid method for multi-step finite rate combustion (Reno, NV), AIAA 95-0205.

Liu, F., Smallwood, G.J. and Gülder, Ö.L. (1999) Radiation heat transfer calculations using the SNBCK method (Norfolk, VA), AIAA paper 99-3679.

McEnally, C.S., Schaffer, A.M., Long, M.B., Pfefferle, L.D., Smooke, M.D., Colket, M.B. and Hall, R.J. (1998) "Computational and experimental study of soot formation in a coflow, laminar ethylene diffusion flame", Twenty-seventh Symposium (Int.) on Combustion (The Combustion Institute, Pittsburgh, USA), pp 1497-1505.

McLintock, I.S. (1968) "The effects of various diluents on soot production in laminar ethylene diffusion flames", Combustion and Flame 12, 217-225.

Neoh, K.G., Howard, J.B. and Sarofim, A.F. (1981) "Soot oxidation in flames", In: Siegla, D.C. and Smith, G.W., eds, Particulate Carbon: Formation During Combustion (New York), pp 261-282.

Patankar, S.V. (1980) Numerical Heat Transfer and Fluid Flow, (Hemisphere, New York).

Schug, K.P., Manheimer-Timnat, Y., Yaccarino, P. and Glassman, I. (1980) "Sooting behavior of gaseous hydrocarbon diffusion flames and the influence of additives", Combustion Science and Technology 22, 235-250.

Smith, G.P., Golden, D.M., Frenklach, M., Moriarty, N.W., Eiteneer, B., Goldenberg, M., Bowman, C.T., Hanson, R.K., Song, S., Gardiner, W.C., Lissianski, J.V.V. and Qin, Z (1999) http://www.me.berkeley. edu/gri mech/.

Smooke, M.D., McEnally, C.S., Pfefferle, L.D., Hall, R.J. and Colket, M.B. (1999) "Computational and experimental study of soot formation in a coflow, laminar diffusion flame", Combustion and Flame 117, 117-139.

Talbot, L., Cheng, R.K., Schefer, R.W.M. and Willis, D.R. (1980) "Thermophoresis of particles in a heated boundary layer", Journal of Fluid Mechanics 101, 737-758.

Warnatz, J. (1982) "Influence of transport models and boundary conditions on flame structure", In: Peters, N. and Warnatz, J., eds, Numerical Methods in Laminar Flame Propagation (Vieweg, Braunschweig), pp 87-111.

Williams, B.A. (2001) "Sensitivity of calculated extinction strain rate to molecular transport formation in nonpremixed counterflow flames", Combustion and Flame 124, 330-333. 